\title{
Arbor
}

\section{El Auto de los Reyes Magos}

\author{
Miguel Ángel Pérez Priegos
}

Arbor CLXXVII, 699-700 (Marzo-Abril 2004), 611-621 pp.

El Auto de los Reyes Magos es nuestra más antigua pieza dramática conservada, compuesta hacia fines del s. XII o comienzos del XIII. El texto, de tradición y procedencia toledana, es producto de una sociedad en la que se cruzan y conviven diversas culturas y lenguas. Lo más probable es que su autor fuera un clérigo de origen francés afincado en Toledo, donde hubo de componer la pieza que conocemos, destinada a una señalada fiesta de la catedral y dentro de una cierta tradición dramática vernácula que. En ella recoge el tema de la adoración de los Magos, común a la tradición del drama litúrgico del Ordo Stellae, pero sin adaptarse ni mucho menos traducir ninguna de sus versiones. Como otros intérpretes de la leyenda de los Magos, hubo de sentirse incitado a interpretarla y recrearla, pero en aquella situación cultural nueva y distinta, pudo llevar a cabo una creación más libre y audaz. Recreó así muchos de los motivos tradicionales (el número y el nombre de los reyes, su condición de estrelleros y magos, el encuentro en el camino, la llegada ante Herodes, la cólera de éste, el ofrecimiento de regalos) y añadió algunos otros fundamentales $y$ de marcado carácter dramático, como la permanente idea de la busca de la verdad que recorre todo el auto, el ofrecimiento de regalos establecido como expectante prueba de la condición del recién nacido o la agitada disputa de los rabinos ante Herodes. De notable calidad teatral son también la construcción de la obra en una sucesión de escenas perfectamente encadenadas, que reclaman un escenario múltiple y simultáneo, su ágil movimiento dramático con medidas referencias al tiempo y al espacio, o el fluido diálogo entre personajes perfectamente individualizados.

La leyenda de los Reyes Magos es posiblemente una de las más fascinantes de nuestra cultura y una de las que ha conseguido mayor fideli- 
dad y adhesiones a lo largo del tiempo. Tal vez lo que muestra de búsqueda, de indagación y persecución de la verdad, o tal vez el contraste que presenta entre lo fastuoso y lo humilde, el poder y la pobreza, o quizá el mundo maravilloso que recrea (la estrella guiadora, el misterio de lo que aparecerá, los regalos mágicos), sean motivos que ayudan a explicar esa perdurabilidad en el tiempo y ese generalizado atractivo que ha despertado.

La historia, como es sabido, se basa en un breve texto del evangelio de San Mateo (2,1-12), en el que se daba cuenta veladamente de la peripecia de unos personajes poderosos y lejanos que, guiados por una estrella, acudieron al nacimiento de Cristo. La historia que allí se insinuaba excitó vivamente la curiosidad de la gente, de manera que se fue fraguando toda una leyenda que reconstruía palmo a palmo lo que el texto de Mateo dejaba en penumbra: los nombres de aquellos personajes, su condición, las incidencias de su viaje, pormenores de su vida e incluso su muerte.

Fue la Edad Media la que alimentó de una manera más insistente la leyenda, estimulada aún por algún magno acontecimiento, como el del hallazgo del cuerpo de los Magos en Milán, en 1158, y su traslado a Colonia en 1164, en cuya catedral todavía se veneran. A lo largo de aquella época, en efecto, se fueron concretando y precisando los datos más interesantes. El número, por ejemplo, que era indeterminado en un principio, quedó fijado en tres a partir de los escritos de Orígenes en el siglo III $^{1}$, aunque la iconografía vaciló en su representación hasta el siglo $\mathrm{VI}^{2}$. El título de reyes se lo asignó primero Tertuliano al sugerir su identificación con los reyes de Arabia y de Saba de que hablaban los Salmos, y lo proclamó abiertamente Cesáreo de Arles en el s. VI («Illi Magi tres reges esse dicuntur») ${ }^{3}$, aunque también aquí la iconografía tardó hasta el $\mathrm{s}$. X en representar a los Magos con corona de reyes en lugar del bonete frigio con que hasta entonces les caracterizaba ${ }^{4}$. En cuanto a los nombres, en su versión latina (Balthassar, Gaspar, Melchior), aparecen por primera vez en 1178 en la Historia Scholastica de Pedro Comestor, y la Legenda aurea (caps. X y XIV) de Jacobo de Voragine los populariza en Occidente en el s. XIII. Aunque no siempre en la tradición de la leyenda los magos son representados como astrólogos, ya Tertuliano como tales los considera («Primi igitur stellarum interpretes natum Christum anubtiauerunt, primi munerauerunt»), y en la obra de Hildeberto de Tours, en 1134, será donde por primera vez aparezca mencionada la frase sancti magi $i^{5}$. De otros motivos, como su encuentro en el camino, la llegada ante Herodes o el ofrecimiento de regalos, trataremos más adelante. 
La leyenda así formada ha tenido tratamiento prácticamente en todas las manifestaciones artísticas y literarias, pero ha sido en el teatro donde desde el principio ha conocido un desarrollo más continuado. Ya en el s. XII cundió en todas las iglesias europeas un breve drama litúrgico conocido como Ordo Stellae, que tenía lugar a continuación del oficio litúrgico de Epifanía y que a lo largo de las naves del templo representaba el seguimiento de los Magos a la estrella ${ }^{6}$. En muchos lugares se desarrollaron luego representaciones sobre el mismo asunto en lengua vulgar, como la documentada en la catedral de Toledo en el s. XV7. En las cortes y palacios nobiliarios prendió igualmente la representación, como, por ejemplo, se documenta en la corte del condestable Miguel Lucas de Iranzo, en Jaén ${ }^{8}$. Continuaría después muy viva en el teatro religioso del siglo XVI, con obras de Gil Vicente o del Códice de autos viejos. Y prendería asimismo en el folclore popular, con representaciones colectivas en pueblos de Murcia o Extremadura.

En la literatura española contamos con una de sus manifestaciones más antiguas en el llamado Auto de los Reyes Magos, que es también nuestra primera pieza teatral conocida. Conservado en un manuscrito de los últimos años del s. XII o primeros del XIII, hoy en la Biblioteca Nacional de Madrid $^{9}$, presenta un texto, aun en su brevedad, asediado de problemas interpretativos, que van de la autoría y la lengua a la originalidad y sentido. La obra, de tradición y procedencia toledana ${ }^{10}$, es producto de una sociedad en la que se cruzan y conviven diversas culturas y lenguas, como sucedía en la Toledo de la época. De una realidad multilingüe como aquélla pudo surgir un texto de amplia base en romance castellano, aunque arcaico y vacilante, al que se incorporan también numerosos mozarabismos, latinismos bíblicos y extranjerismos de lengua franca ${ }^{11}$. Es probable que su autor fuera un clérigo de origen francés o educado en Francia, lo que explicaría el conocimiento de algunos motivos literarios (las modalidades de la leyenda en los poemas populares franceses sobre la Infancia de Cristo), así como los abundantes galicismos. Afincado en Toledo, donde existiría una cierta tradición dramática vernácula, para una señalada fiesta de la catedral como era la del día de la Epifanía, hubo de componer la pieza que conocemos. En ella recoge el tema de la adoración de los Magos, común a la citada tradición del drama litúrgico del Ordo Stellae, pero sin adaptarse ni mucho menos traducir ninguna de sus versiones.

El Auto, en sus ciento cuarenta y siete versos pareados anisosilábicos, pone en escena las intervenciones, en tres monólogos sucesivos, de los tres Magos, ya individualizados con sus respectivos nombres: Caspar, 
Baltasar y Melchior. Los tres son intérpretes del curso de las estrellas y los tres contemplan la estrella maravillosa, dudan, la quieren ver por segunda o tercera vez y finalmente toman la decisión de seguirla. Los tres se encuentran precisamente en ese camino, se comunican sus dudas y se reafirman en su creencia. Pero, cautos, deciden plantear la prueba del ofrecimiento de presentes que será la que les asegure en su certeza al indicarles la condición divina del recién nacido. Llegan ante el rey Herodes, que queda confuso y sorprendido de aquellas noticias. Airado reúne a sus sabios y consejeros, a sus rabinos, que, sin embargo, no sabrán explicarle lo que ocurre, no sabrán decirle verdad.

Nuestro autor hubo de sentir la misma fascinación que su siglo por la leyenda de los Magos, que, como dijimos, dejaba incompleta en sus detalles el evangelio de San Mateo. Como otros intérpretes de la leyenda, hubo de sentirse incitado a interpretarla y recrearla. Bien porque no pesaba sobre él la tradición coercitiva del drama litúrgico, bien porque operaba con una lengua nueva y en una sociedad nueva y singularmente abigarrada, pudo llevar a cabo una creación más libre y audaz. En efecto, el autor anónimo recreó el tema recogiendo motivos de la leyenda procedentes de diversas tradiciones eclesiásticas y populares, como los citados del número y el nombre de los reyes, su condición de estrelleros y magos, el encuentro en el camino, la llegada ante Herodes, la cólera de éste, el ofrecimiento de regalos, etc. Muchos de esos motivos los aceptó sin más y apenas los reelaboró, como hizo con los nombres y el número, para los que aceptó la formulación más extendida. La condición de estrelleros, stellarum interpretes, asociada al milagro y lo maravilloso, sin embargo, la puso más de relieve haciendo que los personajes estudiaran repetidamengte la estrella y poniendo varias veces en su boca la palabra maravilla, resumen del asombro que aquella les producía:

CASPAR Dios criador, quál maravilla.

No sé quál es aquesta estrella.

Agora primas la é veída, poco tiempo á que es nacida ¿Nacido es el criador, que es de las gentes senior?

Non es uerdad, non sé qué digo; Todo esto non uale uno figo ${ }^{12}$.

La peregrinación y el encuentro en el camino es motivo que toma de los poemas franceses del Évangile de l'Enfance. En el camino se conocen y deciden continuar juntos: 


\begin{tabular}{|c|c|}
\hline \multirow[t]{4}{*}{ CASPAR } & Dios vos salve, señor. ¿Sodes vos estrellero? \\
\hline & Dezidme la vertad, de vos sabelo quiero. \\
\hline & ¿Vedes tal maravilla? \\
\hline & Nacida es una estrella. \\
\hline BALTASAR & $\begin{array}{l}\text { Nacido es el Criador, } \\
\text { que de las gentes es señor. }\end{array}$ \\
\hline CASPAR & Iré, lo aoraré. \\
\hline BALTASAR & Yo otrosí rogar lo é. \\
\hline MELCHIOR & $\begin{array}{l}\text { Señores, ¿a quál tierra, o queredes andar? } \\
\text { ¿Queredes ir conmigo al Criador rogar? } \\
\text { ¿Avedeslo veído? Yo lo vo aorar. }\end{array}$ \\
\hline BALTASAR & Nos imos otrosí, sil' podremos fallar. \\
\hline MELCHIOR & Andemos tras el estrella, veremos el logar. \\
\hline
\end{tabular}

Y en el camino planean también presentar los regalos como prueba de la identidad de Cristo. Tales regalos no son sino el oro, el incienso y la mirra, que efectivamente poseían un significado simbólico en la tradición, como ya explicaba Ireneo en el s. II: la mirra significaba la condición de hombre, el oro la de rey y el incienso la de dios («per ea quae obtulerunt munera ostendisse, quis erat qui adorabatur: myrrham quidem quod ipse erat, qui pro mortal humano genere moreretur et sepeliretur; aurum vero, quoniam rex; thus vero quoniam Deus», Contra Haereses, III, 9,2$)^{13}$

CASPAR

MELCHIOR
¿Cuémo podremos provar si es homne mortal o si es rey de tierra o si celestrial? ¿Queredes biene saber cúmo lo sabremos? Oro, mirra y acenso a él ofrecremos. Si fuere rey de tierra, el oro querrá; si fuere omne mortal, la mirra tomará; si rey celestrial, estos dos dexará, tomará el encenso quel' pertenecerá.

\section{CASPAR Y BALT Andemos y así lo fagamos.}

Pero a todo ello el autor pudo añadir aspectos propios y originales, como hace al presentando precisamente como prueba el ofrecimiento de aquellos regalos o al desarrollar la disputa de los rabinos ante Herodes ${ }^{14}$. La decisión de los Reyes de ofrecer sus regalos como prueba de la verdadera identidad de Cristo supera así el mero simbolismo de los regalos, que venía circulando en la tradición de la leyenda, y crea una cierta ten- 
sión dramática que, como apreciaba Bruce W. Wardropper, sólo se resolvería con la elección del recién nacido en la escena final ${ }^{15}$, que sin embargo el texto conservado no recoge. La escena de Herodes consultando a sus sabios, por su parte, aparece en algunas versiones de la tradición dramática, pero nuestra obra es la única que presenta la disputa entre los rabinos.

El tema principal del Auto es la indagación de la verdad, la preocupación por la verdad revelada. Por eso, pone especial énfasis en la actitud de los Magos que escrutan una y otra noche la estrella anunciadora, o que se encuentran de camino y deliberan entre sí y proponen la prueba de los regalos para descubrir la verdad. Y sobre todo, desarrollará con gran cuidado esa escena en el palacio de Herodes y la consulta a sus rabinos acerca del nacimiento de un nuevo rey, que le acaban de anunciar los Magos:

$\begin{array}{ll}\text { HERODES } & \text { ¿Quin uio numquas tal mal? } \\ & \text { iSobre rei otro tal! } \\ & \text { iAún non só io morto } \\ & \text { ¿Re la terra pusto! } \\ & \text { Numquas atal non ui. } \\ & \text { El seglo ua a çaga, } \\ & \text { ia non sé qué me faga. } \\ & \text { Por uertad no lo creo } \\ & \text { ata que io lo ueo. } \\ & \text { Uenga mio maiordoma, } \\ & \text { qui mios aueres toma. } \\ & \text { Idme por mios abades } \\ & \text { i por mis podestades } \\ & \text { i por mios scriuanos } \\ & \text { i por meos gramatgos } \\ & \text { i por mios streleros } \\ & \text { i por mios retóricos: } \\ & \text { dezirm'an la uertad, si iace in escripto } \\ & \text { o si lo saben elos o si lo an sabido. }\end{array}$

Ante la pregunta de Herodes si ha nacido aquel Rey que los Magos han dicho, uno de los rabinos asegura que de ello nada dicen las escrituras que ha consultado («Por ueras uo lo digo / que no lo fallo escripto»). 
El otro, sin embargo, le echa en cara su error y el que no hayan sabido interpretar las escrituras, particularmente las de Jeremías, para terminar lamentando la persistencia de todos en el error:

\begin{tabular}{|c|c|}
\hline RABÍ $1^{\circ}$ & Rei, ¿qué te plaze? He nos uenidos. \\
\hline HERODES & ¿Í traedes uostros escriptos? \\
\hline RABÍ $1^{\circ}$ & Rei, sí traemos, \\
\hline HERODES & $\begin{array}{l}\text { Pus catad, } \\
\text { dezidme la uertad } \\
\text { si es aquel omne nacido, } \\
\text { que esto tres rees m'an dicho. } \\
\text { Di, rabí, la uertad, si tú lo as sabido }\end{array}$ \\
\hline RABÍ $1^{\circ}$ & $\begin{array}{l}\text { Por ueras uo lo digo } \\
\text { que no lo fallo escripto. }\end{array}$ \\
\hline RABÍ $2^{\circ}$ & $\begin{array}{l}\text { ¡Hamihala, cúmo eres enartado! } \\
\text { ¿Por qué eres rabí clamado? } \\
\text { Non entendes las profecías, } \\
\text { las que nos dixo Ieremías. } \\
\text { ¡Par mi lei, nos somos erados! } \\
\text { ¿Por qué non somos acordados? } \\
\text { ¿Por qué non dezimos uertad? }\end{array}$ \\
\hline RABÍ $1^{\circ}$ & Io non la sé, par caridad. \\
\hline RABÍ $2^{\circ}$ & $\begin{array}{l}\text { Porque no la auemos usada } \\
\text { ni en nostras uocas es falada. }\end{array}$ \\
\hline
\end{tabular}

Como vemos, lo que se debate en la disputa de los rabinos es la interpretación correcta de las profecías del Antiguo Testamento y la naturaleza de la verdad, cuestiones intelectuales, propias del renacimiento del siglo XII ${ }^{16}$. Pero también se deja ver un pensamiento severamente cristiano, una proclamación doctrinal de la victoria de la nueva sobre la vieja ley, de la iglesia sobre la sinagoga. En ese sentido debe interpretarse la referencia a las profecías de Jeremías sobre la llegada del Mesías, aunque no parece que el texto aluda a ningún pasaje concreto del libro bíblico, que sí presentaba una condena de los falsos profetas y el anuncio de una nueva alianza ${ }^{17}$. También es posible que esa cita indique que el texto conservado formaba parte de un drama más amplio que continuaría con la Degollación de los Inocentes (Ordo Rachelis), anunciada efectivamente por la profecía de Jeremías: "Vox in Rama audita est, ploratus et ululatus multus: Rachel plorans filios suos, et noluit consolari, quia non sunt» (31, 15, citada en Mateo, 2, 18). 
Aspectos muy notables de la obra, siempre encarecidos por la crítica, son también su construcción teatral en una sucesión de escenas perfectamente encadenadas, que reclaman un escenario múltiple y simultáneo ${ }^{18}$, su ágil movimiento dramático con medidas referencias al tiempo y al espacio, y con el fluido diálogo entre personajes perfectamente individualizados. Precisamente la distribución del parlamento de los personajes ha venido siendo una de las cuestiones más debatidas en el estudio del Auto y ha dado pie a distintas interpretaciones, basadas unas veces en las fuentes iconográficas; otras en la organización interna del texto y sus signos gráficos y siempre en ese carácter individual de los personajes $^{19}$. La referencia temporal de Melchior ante Herodes, que le pregunta por el tiempo que llevan viendo la estrella («Tredze días á, / i mais non auerá, / que la auemos ueida / i bine percebida»), está perfectamente calculada, pues hace exactamente trece días que los Reyes han comenzado a ver la estrella, es decir, ha transcurrido del 24 de diciembre («in achest mes de december» ) al 6 de enero. El texto no ha dejado de sorprender, incluso desde su presentación material como pieza dramática, al hacer alarde de una cierta escritura teatral mediante una serie de signos didascálicos, en combinación de puntos y cruces gráficos, que parecen indicarnos su fragmentación en escenas así como la intervención sucesiva de los personajes.

En cuanto a su final, la crítica en su mayoría ha dado la pieza por inconclusa y falta de una escena última, que no sería otra que la adoración ante el pesebre y el niño recién nacido. No obstante, Hook y Deyermond han defendido que se trata de una obra completa y que se cierra con la escena única y original de la disputa entre los rabinos consejeros de Hero$\operatorname{des}^{20}$. Desde luego, aparte los conceptuales y de sentido, hay argumentos en favor de la integridad del texto conservado. Fernández Vallejo, quien primero lo transcribió, no dice nada de que sea incompleto. Por su parte, la copia del texto en el manuscrito conservado termina perfectamente acabada quedando todavía un cuarto de folio en blanco. Es decir, no se interrumpe la copia ni hay ningún accidente material que nos lo haga sospechar, más bien al llegar al final la letra va agrandándose progresivamente y se cierra con un gran punto, como señal de fin de tarea. Quiere decirse, pues, que el antígrafo de donde se copia — si es que se copia de algún otro texto escrito- ya acababa así, lo que nos obligaría a suponer un original completo y más remoto. Más verosímil nos parece una transcripción desde la representación misma, en la que el copista ha omitido, por ya bien conocida y convencional, la escena de la adoración. Ésta, como en el 1 Auto dos Reis Magos de Gil Vicente, tendría lugar a continuación, sin texto dia- 


\section{El Auto de los Reyes Magos}

logado alguno, sino simplemente con el movimiento de los personajes: los Reyes se acercarían al nacimiento (que ocuparía una nueva mansión en el escenario múltiple y simultáneo) y el Niño aceptaría los tres regalos que le presentan, puesto que es al tiempo hombre, rey y Dios. Con ello se cerraría conceptual y espectacularmente el Auto, dando respuesta a aquella indagación que había movido a tan poderosos y sabios personajes. «Buscaban un dios nuevo, y dicen que le hallaron» ${ }^{21}$.

\section{Notas}

1 «Possunt quidem isti tres... figuram tenere magorum, qui ex Orientis partibus veniunt eruditi paternis libris", In Genesim, Homilia XIV, 3, apud Winifred Sturdevant, The Misterio de los Reyes Magos. Its Position in the Development of the Mediaeval Legend of the Three Kings, Baltimore, Maryland-París, The Johns Hopkins Press-Les Presses Universitaires de France, 1927 (Johnson Reprint Corporation, Nueva York-Londres, 1973), p. 13, quien ha estudiado documentadamente las fuentes de la leyenda.

2 Émile Mâle, L'Art religieux du XIIIe siècle en France. Étude sur l'iconographie du Moyen Âge et sur ses sources d'inspiration, París, Armand Colin, 1948, pp. 403 y ss.

3 Salmos 9-11, "et dabitur illi ex auro Arabiae et rursus reges Arabum et Saba munera offerunt illi. Nam et magos reges habuit fere Oriens»; véase W. Sturdevant, ob. cit., pp. 12-19.

4 É. Mâle, ob cit.

5 W. Sturdevant, ob. cit., p. 12.

${ }^{6}$ Karl Young, The Drama Of Medieval Church [1933], Clarendon Press, Oxford, 1967, vol. II, pp. 29-101.

7 Felipe Fernández Vallejo, Memorias $i$ disertaciones que podrán servir al que escriba la historia de la iglesia de Toledo desde el año MLXXXV en que conquistó dicha ciudad el rei don Alonso VI de Castilla, fols. 477 y ss., ms. del s. XVIII, h. 1785. Puede verse Miguel Ángel Pérez Priego, Teatro medieval, 2. Castilla..., pp. 217 y ss.

8 M. Á. Pérez Priego, Teatro medieval, 2. Castilla, Barcelona, Crítica, 1997, pp. 231239.

9 Se trata de un códice en pergamino (sign.: Vit./5-9), en cuyas dos últimas hojas va copiado el auto. Al frente, el códice lleva la siguiente indicación sobre su contenido: «Hoc continet Cantica canticorum et Lamentationes Ieremias». Al final del códice, ocupando el

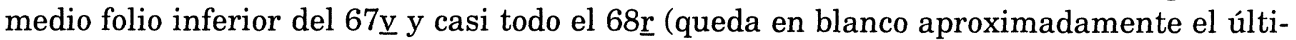
mo cuarto del folio), aparece transcrito el texto del Auto. Éste aparece copiado a renglón seguido, como si fuera prosa, y acompañado de diferentes signos gráficos (combinaciones de cruces y puntos) para indicar, unas veces, separación de versos (un punto) y, otras, cambio de intervención de personaje (una cruz de puntos) o cambio de escena y situación (una cruz más adornada). No hay ningún otro tipo de indicación escénica, didascalia ni nombre de personajes en el diálogo (sólo al final del texto, en línea vertical y al filo del borde derecho del folio, pueden leerse escritos los nombres: "Caspar. Baltasar. Melchior»). Tampoco existe título ni encabezamiento alguno, aunque hay raspadas cuatro líneas iniciales, que, según hacen suponer sus residuos, estarían escritas en letra de cuerpo más pequeño que la del texto del Auto pero semejante a la de la parte latina del códice. 
10 De la catedral de Toledo, desde época muy antigua, procede el códice en que se conserva. Éste contiene en latín las glosas al Cantar de los Cantares y a las Lamentaciones de Jeremías, de Gilberto de la Porrée (+1154), autor que en el siglo XII provocó una extendida controversia por su personal interpretación del dogma de la Trinidad, interpretación de la que se rectractó al aceptar las propuestas de San Bernardo en el concilio de Reims (1148), cuyas resoluciones fueron asimismo promulgadas en Toledo por el arzobispo don Raimundo. Por otro lado, el canónigo de la catedral Felipe Fernández Vallejo, quien describe la representación del Auto en el siglo XVIII, lo presenta indubitablemente como ceremonia y tradición toledana.

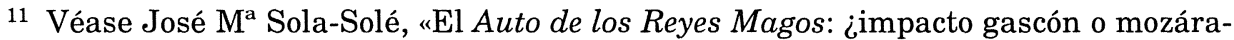
be?», Romance Philology, 29 (1975-1976), 20-27; Olegario García de la Fuente, "Vocabulario bíblico del Auto de los Reyes Magos", Cuadernos para la Investigación de la Literatura Hispánica, 2-3 (1980), 375-382; Rafael Lapesa, "Sobre el Auto de los Reyes Magos: sus rimas anómalas y el posible origen de su autor", en De la Edad Media a nuestros días, Madrid, Gredos, 1967, 37-47; R. Lapesa, «Mozárabe y catalán o gascón en el Auto de los Reyes Magos", en Miscellània Aramon i Serra, Barcelona, Curial, 1983, 277-94. Gerold Hilty, por su parte, ha defendido un origen y autor riojanos para el Auto, que luego transmigraría a Toledo y allí sería transcrito en el texto conservado por un copista que alteraría la forma originari ("La lengua del Auto de los Reyes Magos", en Logos semantikós: studia linguistica in honorem Eugenio Coseriu 1921-1981, Berlín, 1981, V, 289-302; «El Auto de los Reyes Magos: prolegómenos para una edición crítica», en Philologica hispaniensia in honorem Manuel Alvar, Madrid, Gredos, 1983-1986, III, 221-32; “Una vez más: el Auto de los Reyes Magos", en Estudios de lingüística y filología españolas. Homenaje a Germán Colón, Madrid, Gredos, 1998, 229-244; “El Auto de los Reyes Magos, ¿enigma literario y lingüístico?", Actes del VII Congrés de la AHLM, Castellón, 1999, II, 235-44).

12 Las citas del texto se hacen por M. Á. Perez Priego, Teatro medieval, 2. Castilla..., pp. 39-50.

13 Apud W. Sturdevant, ob. cit., p. 12.

14 Diversos críticos han valorado positivamente esos aspectos, como Peter Dronke, La individualidad poética en la Edad Media, trad. esp., Madrid, Alhambra, 1981, o R. Axton, European Drama of the Middle Ages, Hutchinson University Library, Londres, 1974 .

15 Bruce W. Wardropper, "The Dramatic Texture of the Auto de los Reyes Magos", Modern Language Notes, 70 (1955), 46-50.

16 Véase Alan Deyermond, «El Auto de los Reyes Magos y el renacimiento del siglo XII", Actas del IX Congreso de la AIH, Frankfurt, 1989, I, 187-94; y "La Biblia como elemento unificador y divisorio en la literatura medieval de Castilla", en A. Pérez Jiménez y G. Cruz Andreotti, eds., La religión como factor de integración y conflicto en el Mediterráneo, Madrid, Ediciones Clásicas, 1996, 127-156.

17 Es interesante esta vinculación del Auto con el libro de Jeremías: lo primero porque se ha conservado en un códice que contiene precisamente un comentario a las $L a$ mentaciones, y lo segundo, como sugiere Julian Weiss, "The Auto de los Reyes Magos and the Book of Jeremiah", La Corónica, 9 (1981), 128-31, porque «el libro de Jeremías, con su retrato de falsedades profanas y su condena de los falsos profetas, así como el anuncio de una nueva alianza, es concisamente evocado por el drama del Auto".

18 El 6 de enero de 1923, en la casa granadina de la familia García Lorca, se celebró una original representación del Auto de los Reyes Magos en un "teatro planista", de figuras recortadas y pintadas. En el decorado, inspirado en miniaturas de un códice del $D e$ 
natura rerum de la Universidad de Granada, se representaron los árboles del Sol y la Luna enmarcando a la estrella guiadora y a los tres reyes. En aquella fiesta de teatro de títeres, en la que se escenificaron varias obras, tomaron parte el músico Manuel de Falla, el pintor y escenógrafo Hermenegildo Lanz y el poeta Federico García Lorca (Véase Mario Hernández, "Retablo de las maravillas: Falla, Lorca y Lanz en una fiesta granadina de títeres", en Federico García Lorca, Teatro de títeres y dibujos. Con decorados y muñecos de Hermenegildo Lanz, Santander, UIMP-Fundación Federico García Lorca, 1992, 33-52).

19 Véase Ricardo Senabre, «Observaciones sobre el texto del Auto de los Reyes Magos", en Estudios ofrecidos a Emilio Alarcos Llorach, I, Oviedo, Universidad de Oviedo, 1976, 417-32; Juan Manuel Cacho Blecua, "La Representación de los Reyes Magos: texto literario y espectáculo religioso", en Actas del V Congreso de la AHLM, Granada, 1995, pp. 445-461; Miguel Ángel Pérez Priego, ed. cit.

20 David Hook y Alan Deyermond, “El problema de la terminación del Auto de los Reyes Magos", Anuario de Estudios Medievales, 13 (1983 [1985]), 269-78.

21 Luis Cernuda, "La adoración de los Magos», Las Nubes, ed. Luis Antonio de Villena, Madrid, Cátedra, 1991. 